\title{
Community translation in the context of the translation and cross- cultural adaptation of patient reported outcome measures: a South African perspective
}

\author{
*Susan de Klerk, B.OT (SU); DHT (UP); M.OT (SU). https://orcid.org/0000-000 I-7639-93 I 9 \\ Senior Lecturer, Division of Occupational Therapy, Department of Health and Rehabilitation Sciences, Faculty of Medicine and Health \\ Science, Stellenbosch University, Cape Town, South Africa.
}

\author{
Harold M. Lesch, BA; BA-Hons; HDE (UWC); PGDT (UNISA); MA (SU); MDP (SU); DLitt (UWC). \\ https://orcid.org/0000-0003-I474-7028 \\ Associate Professor, Department of Afrikaans and Dutch, Faculty of Arts and Social Sciences, Stellenbosch University, Cape Town, \\ South Africa.
}

Introduction: Occupational Therapists should use relevant patient reported outcome measures as part of providing evidence for occupational therapy intervention. Measures must be responsive, valid and reliable for use in all health sectors. An essential requirement is that the measure be available in the language of the populations it is intended for. As most measures are developed in the English language for use in English speaking countries, we put forward an opinion on the practice of community translation during the translation and cross-cultural adaption of patient reported outcome measures towards increased clinical utility in the public health sector of South Africa.

Keywords: patient reported outcome measures, translation and cross-cultural adaptation, community translation

\section{INTRODUCTION}

Patient reported outcome measures (PROMs) are essential for optimising occupational therapy service delivery. PROMs reflect patient opinion and provide accurate and useful data to guide decision-making and document outcomes. PROMs allow patients to report "symptom status, physical function, mental health, social function, and wellbeing"l:I. The use of these measures in routine clinical practice has the potential to bridge the gap between the view of the therapist and that of the patient as to what has to be prioritised during occupational therapy intervention.

The value of the patients' perspective is a strongly supported notion in emerging research. Legislation and guidelines on the use of PROMs could transform health care around the world as it is essential for providing the best quality care ${ }^{2}$. The implementation of and call for more client-centred approaches - addressing the broader understanding of health brought about by adopting the International Classification of Functioning Disability and Health (ICF) as a framework - allows for the creation of evidence that is based on the patient's perspective, and paves the way for the use of PROMs that assess aspects of activity and participation in addition to the predictable use of instruments that measure a single dimension of body function and structure such as strength or sensation ${ }^{3-5}$. Activity and participation limitations and needs, similar to quality of life, are aspects that are best assessed by the patient ${ }^{2}$.

\section{The Language Measure}

As PROMs ask the patient a series of questions about certain aspects of their health, an essential requirement is for the PROM to be available in the patient's language. As people vary, based on differences in culture, language and occupations, there is a need for measures to be adapted to different contexts. When PROMs are to be used in another language, in another country; it results in a change in language and culture and therefore has to be translated and cross-culturally adapted ${ }^{6}$. The process aims to ensure that the same construct is measured in a different language, between countries and cultures and, in turn, ensures the retention of some measurement properties as well as the conceptual framework of the original version. This is further achieved by following robust guidelines for translation and cross-cultural adaptation as outlined by Beaton et al $^{7}$.

Public health service users in the Western Cape of South Africa (and the Afrikaans language in particular) are of interest in the context of translation and cross-cultural adaptation of PROMs. The under-resourced public health sector largely serves socioeconomically disadvantaged individuals ${ }^{8}$. It has been reported that the public health sector provides care to $84 \%$ of the population and the private health sector $16 \% 9$. Gordon et al. found that economically advantaged households are more likely to have private medical insurance compared to socio-economic disadvantaged households ${ }^{8}$. In $2019,18,8 \%$ of South Africans lived below the international poverty line (R30,46 per day) and $40 \%$ below the lower-bound poverty line (R8I0 per person per month) ${ }^{10}$. Coovadia et al. reported $10 \%$ of persons in the Western Cape to live below poverty and $24 \%$ to be covered by medical schemes" ${ }^{\prime}$. It is therefore postulated that a large percentage of persons in the Western Cape are socioeconomically disadvantaged and make use of the public health 
Table I: Types of Community Translation

\begin{tabular}{|l|l|}
\hline Type of CT & Description \\
\hline Parallel CT & $\begin{array}{l}\text { Where the ST reader and TT reader are of the same SES and the ST is translated in a similar manner for a target group } \\
\text { that has an equivalent educational background. }\end{array}$ \\
\hline Non-parallel CT & $\begin{array}{l}\text { Where the ST reader is more highly skilled and has a higher SES than the potential TT reader. Consequently, the TT } \\
\text { needs to be lowered. }\end{array}$ \\
\hline Intra-lingual CT & $\begin{array}{l}\text { Taking the division between inter-lingual, intra-lingual and inter-semiotic (i.e. signs and symbols that are interpreted e.g. } \\
\text { a green light or an emoji) translation as a point of departure. With intra-lingual CT, a ST is translated intra-lingually in } \\
\text { the sense that it is made accessible to a broader target readership in the same language; the text is thus rewritten into a } \\
\text { simplified version. }\end{array}$ \\
\hline CT approach & $\begin{array}{l}\text { Where the needs of the linguistically disadvantaged are prioritised. In this instance, the commissioner, who is the initia- } \\
\text { tor of the translation process, states in his/her brief to the translator that a functional approach should be used and the } \\
\text { TT be simplified, even though the ST and TT readers are of the same SES. }\end{array}$ \\
\hline
\end{tabular}

CT = Community Translation; ST $=$ Standard Text; TT = Target Text; SES = Socioeconomic Status

service when seeking occupational therapy intervention. It is also believed that persons who are socio-economically disadvantaged may be more likely to have lower levels of education when unable to access better educational opportunities; affecting literacy levels ${ }^{8}$.

The population of interest is Afrikaans-speaking individuals receiving occupational therapy in government hospitals and/or health care facilities within the Western Cape, where the administration of a PROM is common. Afrikaans is spoken by $13.5 \%$ of the population of South Africa and most widely used in the Western and Northern Cape of South Africa ${ }^{12}$. Blignaut ${ }^{20}$ however, highlights that there is great variation in a language that is "fed by differing social, cultural, geographical, situational and psychological contexts"|3:20. As a result, a variety of Afrikaans ${ }^{\mathrm{a}}$ spoken in the Western Cape, sometimes referred to as 'Kaaps' or 'Western Cape Afrikaans', is a colloquial language, spoken by varied communities in the Western Cape ${ }^{14}$. During Apartheid, the Group Areas act separated South Africans according to racial classification in different suburbs ${ }^{15}$. In addition, the Apartheid law restrictions favoured white South Africans and lead to lower socioeconomic status (SES) amongst black, coloured and Indian South Africans ${ }^{10,16}$. Following democratisation in 1994, there has been movement of individuals from low SES area to higher SES areas, although many of the suburbs and their residents have remained the same ${ }^{16}$. The Afrikaans*-speaking persons making use of government health care facilities, situated in or providing health care to low SES areas in the Western Cape of South Africa are of interest in making an argument for community translation during the translation and cross - cultural adaption of PROMs.

\section{Community in Translation (CT)}

The notion of CT as developed by South African translation scholars such as Lesch ${ }^{17}$ is used to address this linguistic imbalance. The viewpoint of CT that is relevant for this paper, is that the source text (ST) reader and the target text (TT) reader are not necessarily of the same SES and that this has implications for their language equivalence ${ }^{17}$. This perspective of CT focuses on that part of society that is excluded from mainstream development. as is supported by Taibi and Uldis ${ }^{18}$. In essence, it is a translation activity aimed at the priorities of the community, where the community is defined as those people of society belonging to a lower SES and is not necessarily a geographical community ${ }^{18}$.

What is of importance in the language use in CT is that terminology be explained and paraphrased and specialised vocabulary be exchanged for plain language in the TT even though it is not the case in the ST. Within the context of CT, the practice of indirect translation, i.e., "any translation based on a source (or sources) which is itself a translation into a language other than the language of the original, or the target language" 19:3 is also relevant.

The problems of rendering a source text in multilingual and multicultural societies in which there are heterogeneous target audiences for a translation (such as in South Africa), is evident. Translators in such societies must consider the heterogeneity of the TT readers of a PROM, or otherwise translation will only be a symbolic gesture which is empty of value and, therefore, will not communicate the construct intended or could evoke the wrong response.

\section{CONCLUSION}

The cultural turn and the subsequent social turn in translation studies mean that language is not only taken at linguistic face value, but that what is implied with language is also considered. The focus has therefore shifted to people and the community within and from which a translation is produced. Translation is therefore no longer seen as a mere linguistic transmission of texts, but as a strategy that brings two cultures, which have (or may have) an unequal power relationship, in contact with each other.

Against this backdrop PROM developers that allow for the translation and cross-cultural adaptation of their instrument trust (and in most instances monitor through having to declare intent to translate and report on the process every step of the way) that researchers or clinicians follow guidelines for translation and cross-cultural adaptation. As a result, many language versions can exist for one PROM. The translation and cross-cultural adaptation should be responsive to the population it is intended for but does not make that version exclusive to a certain group or service user. A PROM that was translated into Afrikaans for the Western Cape through the process of community translation is not exclusively for persons from low SES and low levels of education, but for any person who can identify with the language and cross-cultural adaptations within the PROM. Inversely, persons from low SES backgrounds and potential low levels of education may prefer standard translations of PROMs, for example, standard Afrikaans. Options should be available to ensure accurate self-report. We cannot accept that translation and cross-cultural adaptation of any PROM into the II official languages of South Africa will provide sufficient choice. Community translation should be considered to ensure that PROMs are responsive, valid and reliable following

"For the purpose of this opinion piece, the term Afrikaans is understood to refer to 'community Afrikaans for the Western Cape' or 'Western Cape Afrikaans'. 
translation and cross-cultural adaptations for use in the varied communities within the South African context.

\section{Author Contributions}

Susan de Klerk conceptualized the outline and first draft of this opinion piece based on her research undertaken towards her PhD. Harold Lesch (a scholar in Interpreting and Afrikaans Linguistics) contributed to the subsequent drafts, specifically as it relates to his field of expertise i.e., community translation.

\section{REFERENCES}

I. Nelson EC, Eftimoavska E, Lind C, Hager A, Wasson JH, Lindblad S. Patient reported outcome measures in practice. BMJ Br Med J [Internet]. 2015 [cited 202। Mar 9];350:g78।8: I-3. www.kingsfund.org.uk/publications/proms.html.

2. Black N. Patient reported outcome measures could help transform healthcare. BMJ (Clinical Res ed) [Internet]. 2013;346:fl67. https://doi.org/10.1136/bmj.fl67

3. Schoneveld K, Wittink H, Takken T, Powell R, Wietlisbach C. Clinical commentary in response to: clinimetric evaluation of measurement tools used in hand therapy to assess activity and participation. J Hand Ther [Internet]. 2009;22(3):221-36. https://doi.org//016/j.jht.2009.03.003

4. Weinstock-Zlotnick G, Bear-Lehman J. How therapists specializing in hand therapy evaluate the ability of patients to participate in their daily lives: an exploratory study. J Hand Ther [Internet]. 20I5;28(3):26I-8. https://doi.org/I0.10I6/j.jht.20I4.I2.010.

5. Jack J, Estes RI. Documenting progress: Hand therapy treatment shift from biomechanical to occupational adaptation. Am J Occup Ther [Internet]. 2010;64(I):82-7. https://doi.org/I0.5014/ajot.64.I.82

6. Guillemin F, Bombardier C, Beaton D. Cross-cultural adaptation of health-related quality of life measures: literature review and proposed guidelines. J Clin Epidemiol [Internet]. 1993;46(I2): 1417-32. https://doi.org/10.1016/0895-4356(93)90142-n.

7. Beaton D, Bombardier C, Guillemin F, Bosi-Ferraz M. Guidelines for the process of cross-cultural adaptation of self-report measures. Spine (Phila Pa 1976). 2000;25:3186-91.

8. Gordon T, Booysen F, Mbonigaba J. Socio-economic inequalities in the multiple dimensions of access to healthcare: The case of South Africa. BMC Public Health [Internet]. 2020 Mar 4 [cited 2020 Aug 17];20(I):289. https://bmcpublichealth.biomedcentral.com/ articles/I0.1 I86/s I 2889-020-8368-7

9. South African National Department of Health. National Health Insurance Policy: towards universal health coverage. Gov Gaz [Internet]. 2017 [cited 2020 Aug 17];90(40955): I-80.

https:/www.gov.za/sites/default/files/gcis_ document/201707/40955gon627.pdf

10. Sustainable Development Goals (SDGs) - Counry Report 2019 South Africa [Internet]. Stats SA. [cited 2020 Aug 2I]. http://www.statssa.gov.za/MDG/SDGs_Country_Report_2019_ South_Africa.pdf

II. Coovadia H, Jewkes R, Barron P, Sanders D, Mclntyre D. The health and health system of South Africa: historical roots of current public health challenges. Lancet [Internet]. 2009;374(9692):8I7-34. https://doi.org/10.1016/S0140-6736(09)6095I-X

12. Anthonissen C. "With English the world is more open to you" language shift as a marker of social transformation. English Today [Internet]. 2013 [cited 2017 Nov I5];29(0I):28-35. http://journals.cambridge.org/ENG

13. Blignaut J, Lesch H. 'n Ondersoek na die taalgebruik in Son as verteenwoordigend van Kaaps. Stellenbosch Pap Linguist Plus
[Internet]. 2015 [cited 2017 Nov 15];45: 19.

http://scholar.sun.ac.za/handle/I0019.1/86542

14. Blignaut J, Lesch H. SPiL plus. [Internet]. Vol. 45, Stellenbosch Papers in Linguistics Plus. Department of General Linguistics, Stellenbosch University.; [cited 2017 Nov 15]. 19-4I p.

https://www.ajol.info/index.php/splp/article/view/I I 1939

15. Opsomming van die Wet Op Groepsgebiede, 1950 (Wet No 4 I van 1950) : Unie van Suid-Afrika. [Internet]. Pretoria: Die Staatsdrukker; 1950 [cited 2018 Feb 13]. Available from:

http://www.worldcat.org/title/opsomming-van-die-wet-opgroepsgebiede- I950-wet-no-4 I-van- | 950-unie-van-suid-afrika/ oclc/255433290

16. Turok T, Visagie J, Scheba A. Chapter 4: Social Inequality and Spatial Segregation in Cape Town. In: Van Ham M, editor. Urban SocioEconomic Segregation and Income Inequality A Global Perspective. Springer Nature; 2021. p. 7I-90.

17. Lesch H. From Practice to Theory: Societal Factors as a Norm Governing Principle for Community Translation. In: Taibi M, editor. Translating for the Community. Bloomsbury Publishing; 2018. p. 69-97.

18. Taibi M, Uldis O. Community Translation. Bloomsbury Publishing; 2016.

19. Kittel H. Vicissitudes of Mediation: The Case of Benjamin Franklin's Autobiography. In: Kittel H, Frank A, editors. Interculturality and the Historical Study of Literary Translations. Berlin: Erich Schmidt Verlag; 1991. p. 25-35.

\section{Corresponding Author:}

* Susan de Klerk

Email: sdk@sun.ac.za 